\title{
О.Н. Надоненко
}

\section{О НОРМАТИВНЫХ КРИТЕРИЯХ ОТНЕСЕНИЯ ОРГАНИЗАЦИИ К НЕГОСУДАРСТВЕННЫМ ЭКСПЕРТНЫМ УЧРЕЖДЕНИЯМ}

\begin{abstract}
Статья посвящена проблематике выбора критериев отнесения организации к негосударственным экспертным учреждениям. Автором изучена действующая правовая база, проанализированы позиции в отношении данного вопроса ведущих ученых. Доказывается необходимость принятия специализированного закона, устанавливающего данные критерии.
\end{abstract}

Ключевые слова: негосударственное экспертное учреждение, специализачия, коммерческие и некоммерческие организащии.

Начавшееся в конце прошлого века активное реформирование нашего общества продолжается и сейчас как в гражданском, так и правовом аспектах. Одним из элементов этого процесса является отказ от системы исключительно государственных экспертных учреждений. Согласно статистическим данным о деятельности судов общей юрисдикции за 2013-2018 гг., ежегодно более 180 тыс. постановлений о назначении экспертизы- 64\% всех вынесенных соответствующих постановлений - направляется негосударственным судебноэкспертным учреждениям [1]. Однако действующее законодательство, регулирующее данное направление, до сих пор носит преимущественно декларативный характер.

Законность существования двух видов экспертных учреждений закреплена, например, в п. 60 ст. 5 УПК. Общая структура судебной экспертной системы Российской Федерации представлена в ч. 2, 4 ст. 199 УПК РФ, согласно которой официально выделяют три ее составляющие: государственные экспертные учреждения, иные (негосударственные) экспертные учреждения и эксперты, не работающие в экспертных учреждениях.

Однако специального закона, регламентирующего порядок функционирования данной триады в целом, в настоящий момент не существует. Определена только деятельность государственных экспертных учреждений положениями Федерального закона от 31 мая 2001 г. № 73-Ф3 «О государственной судебно-экспертной деятельности в Российской Федерации». Следует отметить, что в рамках данного Федерального закона была предпринята небольшая попытка компенсировать отсутствие общего законодательства для судебной экспертной системы России. Так, в ст. 41 установлено, что «в соответствии с нормами процессуального законодательства Российской Федерации судебная экспертиза может производиться вне государственных судебноэкспертных учреждений лицами, обладающими специальными познаниями в области науки, техники, искусства или ремесла, но не являющимися государственными судебными экспертами». Однако эта компенсация, на наш взгляд, оказалась несколько односторонней и поэтому неполноценной. Федеральный закон говорит о специалистах, не конкретизируя ни место работы сведущих лиц, ни организационно-правовые формы учреждений или организаций, в которых они трудятся. Более того, согласно указанной статье Ф3 № 73, на таких сведущих лиц распространяются положения, не затрагивающие нормы, относящиеся к руководителю экспертного учреждения. Складывается впечатление, что авторы законопроекта сознательно дистанцировались от какой-либо регламентации деятельности иных (негосударственных) экспертных учреждений, регулируя деятельность только экспертов, не работающих в экспертных учреждениях (далее - частных экспертов).

В настоящий момент мы наблюдаем парадоксальную ситуацию: с одной стороны, законодательно закреплено существование частных экспертов и иных экспертных учреждений (ст. 5, 199 УПК РФ, Ф3 № 73), с другой стороны, отсутствует какой-либо как формальный, так и нормативный критерий, позволяющий отнести то или иное учреждение к негосударственному экспертному учреждению. Более того, положения п. 60 ст. 5 УПК РФ позволяют сделать вывод о том, что учреждение может приобрести правовой статус экспертного лишь потому, что именно в это учреждение поступило постановление о назначении экспертизы, несмотря на то, что до этого факта оно не обладало таким статусом. Следовательно, любое учреждение может быть признано экспертным (негосударственным), а его сотрудники при этом приобретают правовой статус экспертов иного экспертного учреждения, а не частных экспертов. Такое определение правового статуса осложняет признание сведущего лица частным экспертом и приводит к правовым казусам, когда руководителю учреждения, далекому от вопросов права, поручают разъяснить сотруднику его права и ответственность как судебному эксперту.

Усиливают законодательную неопределенность относительно организационно-правовых форм иного экспертного учреждения и два постановления Пленумов Верховного Суда Российской Федерации от 21 декабря 2010 г. № 28 «О судебной экспертизе по уголовным делам» и Пленума Высшего Арбитражного Суда Российской Федерации от 4 апреля 2014 г. № 23 «О некоторых вопросах практики применения арбитражными судами законодательства об экспертизе».

В постановлении Пленума Верховного Суда Российской Федерации в п. 2 указано, что «под негосудар- 
ственными судебно-экспертными учреждениями следует понимать некоммерческие организации (некоммерческие партнерства, частные учреждения или автономные некоммерческие организации), созданные в соответствии с Гражданским кодексом Российской Федерации и Федеральным законом "О некоммерческих организациях”, осуществляющие судебноэкспертную деятельность в соответствии с принятыми ими уставами» (выделено автором. - O.H.), в то время как Пленум Высшего Арбитражного Суда Российской Федерации не указывает ограничения относительно организационно-правовой формы экспертных организаций. Данная позиция отражена в первом пункте пленума. В соответствии с ним «экспертиза может проводиться как в государственном судебноэкспертном учреждении, так и в негосударственной экспертной организации, либо к экспертизе могут привлекаться лица, обладающие специальными знаниями, но не являющиеся работниками экспертного учреждения (организации)» (выделено автором. - O.Н.).

Таким образом, даже материалы Пленумов ВС РФ и ВАС РФ не содержат единой позиции относительно того, какое учреждение или организация могут быть признаны негосударственными экспертными.

Очевидно, что определение негосударственных судебно-экспертных учреждений, озвученное Пленумом ВС РФ, происходит из понятия «учреждение», закрепленного в ст. 123.21 Гражданского кодекса Российской Федерации. Однако такой подход к пониманию того, что следует относить к иным экспертным учреждениям, является не единственным [2. С. 37]. Более того, согласно действующему законодательству Верховный Суд РФ и его Пленум не уполномочены самостоятельно издавать нормы права, о чем уже высказывались замечания со стороны научного сообщества [3. С. 43].

Законодательная неопределенность понятий «негосударственное судебно-экспертное учреждение» и «производство экспертизы экспертом, не работающим в экспертном учреждения» приводит к тому, что ряд авторов начинает выделять в судебно-экспертной системе Российской Федерации спорные категории. Так, E.P. Россинская считает, что «судебные экспертизы проводятся экспертами государственных и негосударственных экспертных учреждений, сотрудниками неэкспертных учреждений, частными экспертами либо иными специалистами» [4. С. 86]. Таким образом, Е.Р. Россинская выделяет государственные и негосударственные экспертные учреждения, а вот экспертов, неработающих в экспертных учреждениях, подразделяет еще на три категории: сотрудников неэкспертных учреждений, частных экспертов и иных специалистов, не поясняя, чем с точки зрения закона они отличаются друг от друга. По нашему мнению, такое разделение излишне и приводит к путанице, так как процессуально они все относятся к одной категории - эксперт, не работающий в экспертном учреждении. Очевидно, что следователю при привлечении сведущего лица, не работающего в экспертном учреждении, необходимо учитывать целый ряд непроцессуальных организационных факторов, которые обеспечат законность произ- водства судебной экспертизы. Например, если частный эксперт работает в неэкспертной организации, то следователю придется учитывать, будет ли он выполнять экспертизу в основное рабочее время или в свободное от работы время; будет ли он использовать оборудование и реагентику своего учреждения или не будет. В зависимости от этого следователю может потребоваться получение разрешения от руководства учреждения на производство сотрудником судебной экспертизы, согласование его рабочего графика, порядка использовании оборудования, реактивов или иных мощностей лаборатории для производства экспертного исследования либо в этом всем не будет необходимости.

Однако эти организационные вопросы не являются процессуальными. Независимо от формы их реализации судебная экспертиза будет назначена в порядке, предусмотренном ч. 4. ст. 199 УПК РФ, и в соответствии с п. 2 ч. 1 ст. 195 УПК РФ в постановлении будут указаны фамилия, имя и отчество эксперта, а не учреждение.

Таким образом, основная проблема для следователя в настоящий момент - это определиться с тем, назначает он экспертизу в иное экспертное учреждение или сведущему лицу, не работающему в экспертном учреждении. Следовательно, мы возвращаемся к основному вопросу - какое учреждение или организация могут быть признаны экспертными. Наиболее верным представляется утверждение, что «определение статуса юридического лица как экспертного или неэкспертного учреждения имеет важное процессуальное и методологическое значение» [5. С. 28].

Если не рассматривать положение п. 60 ст. 5 УПК РФ, согласно которому любое учреждение может приобрести данный статус по факту назначения ее сотруднику судебной экспертизы, то в настоящее время единственное определение этого статуса дано Пленумом Верховного Суда, в котором присутствует два основных критерия - некоммерческий характер учреждения и осуществление судебно-экспертной деятельности в соответствии с уставом. Проанализируем на примере Уральской торгово-промышенной палаты (союза) (далее - палата), насколько данное определение соответствует определяемому понятию.

Согласно Уставу Палаты [6], она является негосударственной некоммерческой организацией (ст. 1 гл. 1), Палата может заниматься приносящей доход деятельность, лишь поскольку это необходимо для выполнения ее уставных задач. Палата не распределяет полученную ею прибыль между членами Палаты (ст. 5 гл. 1). В главе второй Устава «Предмет, цели деятельности, задачи и функции Уральской ТПП» о возможности выполнения судебной экспертизы по поручению судебных, следственных, таможенных и иных уполномоченных государственных органов говорится в четырех пунктах ст. 14 среди 46 функций, выполняемых Палатой.

Таким образом, Палата - некоммерческое учреждение. Производство судебных экспертиз предусмотрено Уставом Палаты. Этого достаточно для суда, чтобы признать Уральскую торгово-промышленную палату негосударственным экспертным учреждением. Следо- 
вательно, в настоящее время постановление о назначении судебной экспертизы должно быть вынесено в адрес Палаты с указанием фамилии, имени, отчества эксперта, а разъяснение прав и ответственности возложено на руководителя Палаты.

Тем не менее в рассматриваемой ситуации возникает сомнение как относительно правовой компетенции руководителя Палаты в части разъяснения им прав и ответственности своему сотруднику, так и достаточности анализа положений Устава для принятия законного решения. На наш взгляд, в положении Пленума Верховного Суда не учтен один важный для судебноэкспертного учреждения критерий, а именно специализация на производстве судебных экспертиз. Такой критерий предусмотрен п. 2 ст. 13 проекта Закона № 306504-6 «О судебно-экспертной деятельности в Российской Федерации»: «Негосударственными судебно-экспертными организациями являются некоммерческие организации, созданные в соответствии с законодательством Российской Федерации, к основнылм видам деятельности которых относится судебноэкспертная деятельность, осуществляемая в соответствии с установленными требованиями к производству судебной экспертизы» [7] (выделено автором. - O.Н.).

С учетом данного критерия, если мы изучим не Устав, а выписку из Единого государственного реестра юридических лиц, то увидим, что судебно-экспертная деятельность Палаты отнесена к дополнительным видам деятельности. Следовательно, согласно проекту закона, Палату нельзя будет признать иной экспертной организацией, и постановление должно быть вынесено в адрес конкретного исполнителя, а разъяснение прав и ответственности эксперту выполнено самим следователем.

Несмотря на наши сомнения, в настоящее время Палата может быть признана иным экспертным учреждением. Однако в случае принятия Федерального закона с существующим определением негосударственного экспертного учреждения она этот статус потеряет.
По нашему мнению, положение о специализации учреждения на производстве судебной экспертизы должно присутствовать в определении негосударственного экспертного учреждения. Представляется неприемлемым «демонизация» коммерческих организаций и упование на то, что если организация будет носить некоммерческий характер, то она обеспечит беспристрастность, объективность и качество производства судебной экспертизы автоматически, что, на наш взгляд, является неверным. «Судебно-экспертная деятельность по своей специфике не может и не должна быть нацелена на извлечение прибыли, поскольку выводы эксперта не могут и не должны находиться в какой-либо зависимости от желания и воли “заказчика" экспертных работ» [8. С. 73]. Но как быть тогда с категорией экспертов, не работающих в экспертном учреждении. Для многих производство экспертиз является средством для существования, т.е. они «нацелены на извлечение прибыли». Выделяя категорию «частные эксперты-профессионалы, у которых эта деятельность является основной» [4. С. 86], E.P. Россинская не замечает этого противоречия. С точки зрения оплаты труда и заинтересованности в прибыли эти эксперты не отличаются от экспертов иных экспертных коммерческих учреждений. Однако относительно них нет возражений ни у уважаемых авторов, ни в проекте Федерального закона об экспертной системе в Российской Федерации.

Как уже было отмечено, выводы эксперта зависят не от организационно-правовых форм учреждения, а исключительно от личностных установок эксперта. Поэтому мы полагаем, что недопустимо такое предвзятое отношение к сотрудникам коммерческого сектора экономики.

Считаем, что отсутствие законодательного определения категории негосударственных экспертных учреждений осложняет работу всей правоохранительной системы и требует скорейшего разрешения.

\section{ЛИТЕРАТУРА}

1. Шувалова M. Новый закон о судебно-экспертной деятельности может быть принят уже в этом году. URL: http://www.garant.ru/news/1276588/\#ixzz6IAd9D9mg (дата обращения: 02.05.2020).

2. Хазиев Ш.Н. Об уголовно-процессуальном понятии судебно-экспертного учреждения // Теория и практика судебной экспертизы. 2007. № 5 (1). С. 36-39.

3. Вершицкая Г.В. Правовые особенности осуществления негосударственной экспертной деятельности // Вестник Поволжского института управления. 2014. № 2 (41). С. 41-46.

4. Россинская E.P. Судебная экспертиза в гражданском, арбитражном, административном и уголовном процессе. 3-е изд., доп. М. : Норма : ИНФРА-М, 2014. $736 \mathrm{c.}$

5. Россинская Е., Галяшина Е. Негосударственные экспертные учреждения. Их правовой статус и организационные формы // Законность. 2009. № 2. С. 28-32.

6. Устав Палаты. URL: http://uralcci.com/about/charter/ (дата обращения: 02.05.2020).

7. Законопроект № 306504-6 «О судебно-экспертной деятельности в Российской Федерации». URL: https://sozd.duma.gov.ru/ bill/306504-6 (дата обращения: 02.05.2020).

8. Россинская Е.Р., Галяшина Е.И. Настольная книга судьи: судебная экспертиза. М. : Проспект, 2011. 464 с.

\section{On Regulatory Criteria for Classifying an Organization as a Non-State Expert Institution}

Ugolovnaya yustitsiya - Russian Journal of Criminal Law, 2020, no. 16, pp. 123-126. DOI: 10.17223/23088451/16/23

Olga N. Nadonenko, Yekaterinburg Branch of the Moscow Academy of the Investigative Committee of the Russian Federation (Yekaterinburg, Russian Federation). E-mail: uc.ural@mail.ru

Keywords: non-state expert institution, specialization, commercial organizations and nonprofit organizations. 
The current legislation formalizes three elements of the expert system in Russia: state and non-state expert institutions and experts who do not work in expert institutions. As follows from this triad, the defining concept is "expert institution". The concept "state expert institution" is legally enshrined in Federal Law No. 73-FZ of May 31, 2001, but there is currently no legislative regulation of the criteria for classifying an organization as a "non-state expert institution", which gives rise to a number of law enforcement problems. For instance, for an investigator, determining the status of an organization entails the implementation of the provisions of Article 199 of the Criminal Procedure Code of the Russian Federation under Clause 1.2 or Clause 4. Therefore, in the author's opinion, it is extremely important to pass a law regulating the criteria for classifying an organization as a state or non-state expert institution, or a non-expert institution.

\section{References}

1. Shuvalova, M. (2019) Novyy zakon o sudebno-ekspertnoy deyatel'nosti mozhet byt' prinyat uzhe v etom godu [A new law on forensic expert activities may be adopted this year]. [Online] Available from: http://www.garant.ru/news/1276588/\#ixzz6IAd9D9mg (Accessed: 2nd May 2020).

2. Khaziev, Sh.N. (2007) Ob ugolovno-protsessual'nom ponyatii sudebno-ekspertnogo uchrezhdeniya [On the criminal procedural concept of a forensic institution]. Teoriya i praktika sudebnoy ekspertizy - Theory and Practice of Forensic Science. 5 (1). pp. 36-39.

3. Vershitskaya, G.V. (2014) Legal Features of Non-Governmental Expert Activity. Vestnik Povolzhskogo instituta upravleniya - Bulletin of the Volga Region Institute of Administration. 2(41). pp. 41-46. (In Russian).

4. Rossinskaya, E.R. (2014) Sudebnaya ekspertiza v grazhdanskom, arbitrazhnom, administrativnom i ugolovnom protsesse [Forensic examination in civil, arbitration, administrative, and criminal procedure]. 3rd ed. Moscow: Norma: INFRA-M.

5. Rossinskaya, E. \& Galyashina, E. (2009) Negosudarstvennye ekspertnye uchrezhdeniya. Ikh pravovoy status i organizatsionnye formy [Non-state expert institutions. Their legal status and organizational forms]. Zakonnost'. 2. pp. 28-32.

6. Ural Chamber of Commerce and Industry. (2020) Ustav [Charter]. [Online] Available from: http://uralcci.com/about/charter/ (Accessed: 2nd May 2020)

7. Russian Federation. (2020) Zakonoproekt № 306504-6 O sudebno-ekspertnoy deyatel’nosti v Rossiyskoy Federatsii [Draft Law No. 306504-6 On Forensic Expert Activity in the Russian Federation]. [Online] Available from: https://sozd.duma.gov.ru/bill/306504-6 (Accessed: 2nd May 2020).

8. Rossinskaya, E.R. \& Galyashina, E.I. (2011) Nastol'naya kniga sud'i: sudebnaya ekspertiza [Judge's Handbook: Forensic Expert Examination]. Moscow: Prospekt. 